\title{
Role of polymorphisms of toll-like receptor (TLR) 4, TLR9, toll-interleukin 1 receptor domain containing adaptor protein (TIRAP) and FCGR2A genes in malaria susceptibility and severity in Burundian children
}

Susanna Esposito ${ }^{1}$, Claudio Giuseppe Molteni ${ }^{1}$, Alberto Zampiero', Elena Baggi ${ }^{1}$, Anna Lavizzari ${ }^{1}$, Margherita Semino ${ }^{1}$, Cristina Daleno ${ }^{1}$, Michela Groppo $^{1}$, Alessia Scala ${ }^{1}$, Leonardo Terranova ${ }^{1}$, Monica Miozzo $^{2}$, Claudio Pelucchi ${ }^{3}$ and Nicola Principi ${ }^{1 *}$

\begin{abstract}
Background: Malaria caused by Plasmodium falciparum is one of the leading causes of human morbidity and mortality from infectious diseases, predominantly in tropical and sub-tropical countries. As genetic variations in the toll-like receptors (TLRs)-signalling pathway have been associated with either susceptibility or resistance to several infectious and inflammatory diseases, the supposition is that single nucleotide polymorphisms (SNPs) of TLR2, TLR4, TLR9, Toll-interleukin 1 receptor domain containing adaptor protein (TIRAP) and FCGR2A could modulate malaria susceptibility and severity.

Methods: This study was planned to make a further contribution to solving the problem of the real role of the most common polymorphisms of TLR4, TLR9, TIRAP and FCGR2A genes in modulating the risk of malaria and disease severity in children from Burundi, Central Africa. All the paediatric patients aged six months to 10 years admitted to the hospital of Kiremba, Burundi, between February 2011 and September 2011, for fever and suspicion of acute malaria were screened for malaria parasitaemia by light microscopy of thick and thin blood smears. In children with malaria and in uninfected controls enrolled during the study period in the same hospital, blood samples were obtained on filter paper and TLR4 Asp299Gly rs4986790, TLR9 G1174A rs352139, T-1486 C rs187084 TLR9 T-1237 C rs5743836, TIRAP Ser180Leu rs8177374 and the FCGR2A His131Arg rs1801274 polymorphisms were studied using an ABI PRISM 7900 HT Fast Realtime instrument.

Results: A total of 602 patients and 337 controls were enrolled. Among the malaria cases, 553 (91.9\%) were considered as suffering from uncomplicated and 49 (8.1\%) from severe malaria. TLR9 T1237C rs5743836CC was associated with an increased risk of developing malaria $(p=0.03)$, although it was found with the same frequency in uncomplicated and severe malaria cases. No other differences were found in all alleles studied and in genotype frequencies between malaria cases and uninfected controls as well as between uncomplicated and severe malaria cases.
\end{abstract}

Conclusions: TLR9 T1237C seems to condition susceptibility to malaria in Burundian children but not its severity, whereas none of the assessed SNPs of TLR4, TIRAP and FCGR2A seem to influence susceptibility to malaria and disease severity in this population.

Keywords: Children, cerebral malaria, FCGR2A, malaria, SNPs, toll-like receptors, TIRAP, TLR4, TLR9, uncomplicated malaria.

\footnotetext{
*Correspondence: nicola.principi@unimi.it

'Pediatric Clinic 1, Università degli Studi di Milano, Fondazione IRCCS Ca'

Granda Ospedale Maggiore Policlinico, Via Commenda 9, 20122, Milan, Italy

Full list of author information is available at the end of the article
} 


\section{Background}

Malaria caused by Plasmodium falciparum is one of the leading causes of human morbidity and mortality from infectious diseases, predominantly in tropical and subtropical countries [1]. However, manifestations of the $P$. falciparum infection can vary significantly from patient to patient, ranging from asymptomatic infection to severe life-threatening disease [2]. Together with parasite virulence phenotypes and level of parasitaemia, the host's immune response to the infectious agent has been considered one of the most important conditioning factors of malaria susceptibility and severity, with the first immune response to P. falciparum strictly related to the activity of toll-like receptors (TLRs) [3]. TLRs are a group of trans-membrane proteins, present in monocytes, macrophages and dendritic cells that play a crucial role in the innate immune system. This operates by differentially recognizing pathogen-associated molecular patterns through their extracellular receptor modules and initiating inflammatory signalling pathways through an intracellular domain [4]. Several studies have demonstrated that TLR2, TLR4 and TLR9 are involved in the recognition of $P$. falciparum ligands and that, when encountering the parasite, they elicit a complex cascade of signalling events. These culminate in trans-activation of a repertoire of pro-inflammatory cytokines, such as interferon (IFN)- $\gamma$, interleukin (IL)-12 and tumour necrosis factor (TNF) that should favour the elimination of the infectious agent [5-9]. However, it has been reported that excessive serum levels of these pro-inflammatory cytokines can be frequently found in most of the severe malaria cases [10-14]. Consequently, because genetic variations in the TLR- signalling pathway have been associated with either susceptibility or resistance to several infectious and inflammatory diseases, the supposition is that single nucleotide polymorphisms (SNPs) of TLR2, TLR4 and TLR9 could modulate malaria susceptibility and severity [15]. Moreover, because the Tollinterleukin 1 receptor domain containing adaptor protein (TIRAP) mediates downstream signalling of TLR2 and TLR4 inducing pro-inflammatory response and a SNP of this protein has been reported to diminish TLR2 signalling [16], it has been considered possible that genetic variations of TIRAP could modify host response to $P$. falciparum infection. Finally, genetic variants of FCGR2A, an immunoglobulin G receptor, could be associated with an increased risk of malaria because of a significant reduction in its binding capacity for IgG and $C$ reactive protein (CRP) and the consequent reduced phagocytosis of IgG and CRP opsonized structures [17]. However, studies specifically planned to evaluate the importance of genetics in conditioning susceptibility to and clinical manifestations of malaria have reported conflicting results for all these genetic variants [18-31].
This study was planned to make a further contribution to solving the problem of the real role of the most common polymorphisms of TLR4, TLR9, TIRAP and FCGR2A in modulating the risk of malaria and disease severity. It was carried out in Burundi, a Central African country where malaria is highly endemic perennially and for which no data on relationships between genetics and malaria are available at present.

\section{Methods}

\section{Study population and recruitment}

This study, approved by the Ethical Committee of the Fondazione IRCCS Ca' Granda, Ospedale Maggiore Policlinico, Milan, Italy, and the hospital of Kiremba, Burundi, was carried out in the hospital of Kiremba, a small town located in the district of Ngozi in the northern part of Burundi, between February 2011 and September 2011.

All the paediatric patients aged six months to 10 years admitted to the hospital of Kiremba, Burundi, for fever and suspicion of acute malaria were screened for malaria parasitaemia by light microscopy of thick and thin blood smears, with two independent readers. If informed written or verbal (in case of illiteracy) consent was obtained from a parent or legal guardian, children for whom both readers were positive for the presence of $P$. falciparum were enrolled and grouped according to disease severity in accordance with World Health Organization criteria [32]. In particular, uncomplicated malaria was diagnosed when children had symptoms and signs of malaria (fever, chills, vomiting, headache), P. falciparum on blood smear, and no evidence of malaria complications. Severe malaria was diagnosed in presence of cerebral malaria [repeated seizures or coma (Blantyre coma scale $\leq 2$ or Glasgow coma scale $\leq 8$ )], circulatory collapse, respiratory distress, or haemoglobin level $<5 \mathrm{~g} / \mathrm{dL}$. Otherwise healthy children seen in the hospital during the study period for minor surgery with a similar sex and age distribution and without asymptomatic parasitaemia according to the results of the screening with thick and thin films were enrolled as uninfected controls.

Blood samples were obtained from all the children at enrolment, both cases and controls. Blood was collected on filter paper (LTA, Brugherio, MI) for future DNA extraction and testing and kept in a cool, dry place. Samples collected were sent in the central laboratory in the Department of Maternal and Paediatric Sciences of the University of Milan, Italy, by airmail, once a month, for genetic studies.

\section{DNA extraction and SNP identification}

The blood spots on filter paper were cut into little fragments, then incubated for 1 hour in 3- $\mathrm{mL}$ lysis buffer at room temperature on an orbital shaker. Paper residues were separated from lysate by brief spinning. DNA from all samples was then extracted with a NucliSens EasyMAG 
instrument (Biomerieux, Bagno a Ripoli [FI], Italy), using the Specific B protocol. The DNA extracted was quantified using a Nanodrop ND-1000 instrument (Thermo Fisher Scientific, Waltham, MA, USA), with elution buffer as blank. SNP genotyping was then performed on genomic DNA using pre-designed Taqman ${ }^{\circledR}$ SNP Genotyping assays (Applied Biosystems by Life Technologies, Monza, Italy) [33,34]. SNP selection was based on previously reported associations with malaria in populations of different ethnicities. The nonsynonymous SNP of TLR4 Asp299Gly (rs4986790, assay code C_11722238_20), the intronic SNP of TLR-9 G(1174) A (rs352139, assay code C__2301953_10), the two promoter SNPs of TLR-9 at positions T(-1486)C (rs187084, assay code C_2301952_10) and T(-1237)C (rs5743836, assay code C_32645383_10), the TIRAP/MAL Ser180Leu (rs8177374, assay code C_25983622_10) and the FCGR2A His131Arg non- synonyimous SNPs (rs1801274, assay code C_ 9077561_20) were then studied. Reactions and an allelic discrimination analysis were performed on an $\mathrm{ABI}$ PRISM 7900 HT Fast Real-time instrument (Applied Biosystems).

\section{Statistical analysis}

Data were analysed using SAS for Windows v. 9.1 (SAS Institute, Cary, NC, USA). Categorical variables are presented as numbers and percentages, and were analysed using contingency tables and the chi-squared or Fisher's exact test, as appropriate. The Hardy-Weinberg equilibrium (HWE) was performed by comparing the numbers observed of different genotypes with those expected under the HWE for the estimated genotype frequencies and $p>0.05$ was in HWE. Genotyping deviations from HWE were assessed under Pearson's chi-square $\left(X^{2}\right)$ or the likelihood-ratio statistical test, as appropriate $[35,36]$. Odds ratios and the corresponding $95 \%$ confidence intervals (CI) were calculated to measure the association between genetic variation in selected genes and risk of malaria overall and severe malaria.

\section{Results}

A total of 602 patients (346 males; mean age \pm standard deviation, $5.3 \pm 4.4$ years) and 337 uninfected controls (196 males; mean age \pm standard deviation, $5.4 \pm 4.3$ years) were enrolled. Among uninfected controls, 106 (31.4 \%) were admitted for abdominal surgery, 79 (23.4 \%) for orthopaedic surgery, 69 (20.5\%) for urogenital surgery, 55 $(16.3 \%)$ for plastic surgery and 28 (8.3\% for otolaryngology surgery. Among malaria cases, 553 (91.9\%) were considered as suffering from uncomplicated malaria and 49 (8.1\%) from severe malaria $(12,24.5 \%$, with cerebral malaria; $37,75.5 \%$, with severe anemia). Table 1 shows the

Table 1 Allele frequencies in the study population for the selected SNPs

\begin{tabular}{|c|c|c|c|c|c|c|}
\hline \multirow{2}{*}{$\begin{array}{l}\text { Gene and } \\
\text { polymorphic alleles }\end{array}$} & \multicolumn{6}{|l|}{ Allele frequency } \\
\hline & $\begin{array}{l}\text { Uninfected } \\
\text { controls }(n=337)\end{array}$ & $\begin{array}{l}\text { Children with } \\
\text { malaria }(n=602)\end{array}$ & $P$ value & $\begin{array}{l}\text { Children with } \\
\text { uncomplicated } \\
\text { malaria }(n=553)\end{array}$ & $\begin{array}{l}\text { Children with } \\
\text { severe malaria } \\
(n=49)\end{array}$ & P value \\
\hline \multicolumn{7}{|c|}{ TLR4 Asp299Gly rs4986790 } \\
\hline Asp & 0.94 & 0.94 & & 0.93 & 0.98 & \\
\hline Gly & 0.06 & 0.06 & 0.55 & 0.07 & 0.02 & 0.07 \\
\hline \multicolumn{7}{|c|}{ TLR9 G1174A rs352139 } \\
\hline G & 0.51 & 0.53 & & 0.52 & 0.57 & \\
\hline A & 0.49 & 0.47 & 0.61 & 0.48 & 0.43 & 0.36 \\
\hline \multicolumn{7}{|c|}{ TLR9 T1486C rs187084 } \\
\hline $\mathrm{T}$ & 0.75 & 0.75 & & 0.76 & 0.72 & \\
\hline C & 0.25 & 0.25 & 0.94 & 0.24 & 0.28 & 0.45 \\
\hline \multicolumn{7}{|c|}{ TLR9 T1237C rs5743836* } \\
\hline $\mathrm{T}$ & 0.68 & 0.63 & & 0.63 & 0.63 & \\
\hline C & 0.32 & 0.37 & 0.04 & 0.36 & 0.37 & 0.93 \\
\hline \multicolumn{7}{|c|}{ TIRAP Ser180Leu rs8177374 } \\
\hline Ser & 0.98 & 0.97 & & 0.97 & 0.98 & \\
\hline Leu & 0.02 & 0.03 & 0.50 & 0.03 & 0.02 & 0.59 \\
\hline \multicolumn{7}{|c|}{ FCGR2a H131R rs1801274 } \\
\hline His & 0.45 & 0.43 & & 0.42 & 0.45 & \\
\hline Arg & 0.55 & 0.57 & 0.58 & 0.58 & 0.55 & 0.61 \\
\hline
\end{tabular}

Significant difference between uninfected controls and children with malaria for TLR9 T1237C rs5743836 only. No difference between children with uncomplicated malaria and those with severe malaria. 
allele frequencies for the selected SNPs in P. falciparuminfected children and in controls. All SNPs examined were present in the study populations. However, minor allele frequencies for TLR4 Asp299Gly and for TIRAP Ser180Leu were less than $10 \%$ in patients regardless of disease severity $(2.1 \%$ to $7.0 \%$ for TLR4 Asp299Gly, $2.1 \%$ to $3.0 \%$ for TIRAP Ser180Leu) and controls (6 \% for TLR4 Asp299Gly and $2.4 \%$ for TIRAP Ser180Leu). On the contrary, minor allele frequency for the other SNPs studied exceeded $>20 \%$ in all cases, reaching values around $40 \%$ (42.3\%-45.2 \%) and $50 \%$ (43.0\%-48 \%) for FCGR2A His131Arg and TLR9 G1174A, respectively. TLR9 T1237C rs5743836 C was found significantly more frequently in children with malaria than in uninfected controls $(p=0.04)$, although no difference was found between children with uncomplicated and those with severe malaria. No other significant difference among Burundian children with malaria and related controls was found as well as between children with uncomplicated and those with severe malaria for all the other allele frequencies studied ( $\mathrm{P}>0.05$ for all the other comparisons).

Table 2 shows the genotype frequencies for SNPs studied comparing children with malaria and uninfected controls, whereas Table 3 summarizes the genotype frequencies for SNPs studied comparing children with uncomplicated malaria and those with severe malaria. For TLR4, TLR9 and FCGR2A frequency of the genetic variants was as expected, whereas genotyping for TIRAP Ser180Leu variants showed slight deviations from what would be expected under the HWE in the control group $(\mathrm{p}<0.001)$. TLR9 T1237C rs5743836CC was associated with an increased risk of developing malaria $(p=0.03)$, although it was found with the same frequency in uncomplicated and severe malaria cases. No other differences in all the allele and genotype frequencies studied were found between malaria cases and uninfected

Table 2 Genotype frequencies comparing uninfected controls and children with malaria for the selected SNPs

\begin{tabular}{|c|c|c|c|c|c|c|c|}
\hline \multicolumn{8}{|c|}{ Genotype frequency } \\
\hline \multirow{2}{*}{$\begin{array}{l}\text { Gene and } \\
\text { polymorphic } \\
\text { alleles }\end{array}$} & \multicolumn{2}{|c|}{ Observed } & \multicolumn{2}{|c|}{ Expected } & \multirow[t]{2}{*}{$P\left(H W E, X^{2}\right)$} & \multirow[t]{2}{*}{ OR $(95 \% \mathrm{Cl})$} & \multirow[t]{2}{*}{$P$ value } \\
\hline & $\begin{array}{l}\text { Uninfected } \\
\text { controls }(n=337)\end{array}$ & $\begin{array}{l}\text { Children with } \\
\text { malaria }(n=602)\end{array}$ & $\begin{array}{l}\text { Uninfected controls } \\
(n=337)\end{array}$ & $\begin{array}{l}\text { Children with } \\
\text { malaria }(n=602)\end{array}$ & & & \\
\hline \multicolumn{8}{|c|}{ TLR4 Asp 299Gly rs4986790 } \\
\hline Asp/Asp & $300(89.0)$ & $528(87.7)$ & $300(89.0)$ & $528(87.7)$ & Controls $=0.94$ & 1 (reference) & \\
\hline Asp/Gly & $36(10.7)$ & $72(11.9)$ & $36(10.7)$ & $71(11.8)$ & Malaria $=0.78$ & $1.14(0.73-1.79)$ & 0.55 \\
\hline Gly/Gly & $1(0.3)$ & $2(0.3)$ & $1(0.3)$ & $3(0.5)$ & & $1.14(0.06-67.3)$ & 0.92 \\
\hline \multicolumn{8}{|c|}{ TLR9 G1174A rs352139 } \\
\hline GG & $92(27.3)$ & $166(27.5)$ & $89(26.4)$ & $167(27.8)$ & Controls $=0.56$ & 1 (reference) & \\
\hline GA & $163(48.4)$ & $302(50.2)$ & $169(50.2)$ & $300(49.8)$ & Malaria $=0.88$ & $1.03(0.74-1.43)$ & 0.87 \\
\hline AA & $82(24.3)$ & $134(22.3)$ & $79(23.4)$ & $135(22.4)$ & $0.91(0.61-1.34)$ & 0.60 & \\
\hline \multicolumn{8}{|c|}{ TLR9 T1486C rs187084 } \\
\hline$\pi$ & $197(58.4)$ & $342(56.8)$ & $191(56.7)$ & $340(56.5)$ & Controls $=0.07$ & 1 (reference) & \\
\hline $\mathrm{TC}$ & $113(33.6)$ & $220(36.6)$ & $125(37.1)$ & $223(37.0)$ & Malaria $=0.57$ & $1.12(0.83-1.51)$ & 0.43 \\
\hline $\mathrm{CC}$ & $27(8.0)$ & $40(6.6)$ & $21(6.2)$ & $39(6.5)$ & & $0.85(0.49-1.49)$ & 0.55 \\
\hline \multicolumn{8}{|c|}{ TLR9 T1237C rs5743836 } \\
\hline$\Pi$ & $155(46.0)$ & $245(40.6)$ & $155(46.0)$ & $238(39.5)$ & Controls $=0.99$ & 1 (reference) & \\
\hline $\mathrm{TC}$ & $147(43.6)$ & $267(44.4)$ & $147(43.6)$ & $280(46.5)$ & Malaria $=0.22$ & $1.15(0.86-1.54)$ & 0.34 \\
\hline $\mathrm{CC}$ & $35(10.4)$ & $90(15.0)$ & $35(10.4)$ & $84(14.0)$ & & $1.63(1.03-2.60)$ & 0.03 \\
\hline \multicolumn{8}{|c|}{ TIRAP S180L rs8177374* } \\
\hline Ser/Ser & $324(96.1)$ & $567(94.2)$ & $321(95.3)$ & $567(94.2)$ & Controls $=<0.001$ & 1 (reference) & \\
\hline Ser/Leu & $10(3.0)$ & $35(5.8)$ & $16(4.7)$ & $34(5.6)$ & Malaria $=0.46$ & $2.00(0.98-4.09)$ & 0.06 \\
\hline Leu/Leu & $3(0.9)$ & 0 & $0(0.0)$ & $1(0.2)$ & & - & - \\
\hline \multicolumn{8}{|c|}{ FCGR2a H131R rs1801274 } \\
\hline His/His & $76(22.6)$ & $108(17.9)$ & $73(21.7)$ & $110(18.3)$ & Controls $=0.10$ & 1 (reference) & \\
\hline His/Arg & $152(45.1)$ & $299(49.7)$ & $159(47.2)$ & $295(49.0)$ & Malaria $=0.72$ & $1.38(0.96-2.00)$ & 0.07 \\
\hline Arg/Arg & $109(32.3)$ & $195(32.4)$ & $105(31.1)$ & $197(32.7)$ & & $1.26(0.85-1.86)$ & 0.23 \\
\hline
\end{tabular}

Percentages in brackets. $\mathrm{Cl}$, confidence interval; HWE, Hardy-Weinberg equilibrium. 
Table 3 Genotype frequencies comparing uninfected controls and children with malaria for the selected SNPs

\begin{tabular}{|c|c|c|c|c|c|c|c|}
\hline \multirow{3}{*}{$\begin{array}{l}\text { Gene and } \\
\text { polymorphic } \\
\text { alleles }\end{array}$} & \multicolumn{4}{|c|}{ Genotype frequency } & \multirow{3}{*}{$\mathrm{P}\left(\mathrm{HWE}, \mathrm{X}^{2}\right)$} & \multirow{3}{*}{ OR $(95 \% \mathrm{Cl})$} & \multirow{3}{*}{$P$ value } \\
\hline & \multicolumn{2}{|c|}{ Observed } & \multicolumn{2}{|c|}{ Expected } & & & \\
\hline & $\begin{array}{l}\text { Children with } \\
\text { uncomplicated } \\
\text { malaria }(n=553)\end{array}$ & $\begin{array}{l}\text { Children with } \\
\text { severe malaria } \\
(n=49)\end{array}$ & $\begin{array}{l}\text { Children with } \\
\text { uncomplicated } \\
\text { malaria }(n=553)\end{array}$ & $\begin{array}{l}\text { Children with } \\
\text { severe malaria } \\
(n=49)\end{array}$ & & & \\
\hline \multicolumn{8}{|c|}{ TLR4 Asp 299Gly rs4986790 } \\
\hline Asp/Asp & $481(86.9)$ & 47 (95.9) & $481(86.9)$ & $47(95.9)$ & Uncomplicated malaria $=0.74$ & 1 (reference) & \\
\hline Asp/Gly & $70(12.7)$ & $2(4.1)$ & $69(12.5)$ & $2(4.1)$ & Severe malaria $=0.88$ & $0.29(0.03-1.16)$ & 0.08 \\
\hline Gly/Gly & $2(0.4)$ & $0(0.0)$ & $3(0.6)$ & & & - & - \\
\hline \multicolumn{8}{|c|}{ TLR9 G1174A rs352139 } \\
\hline GG & $149(27.0)$ & $17(34.7)$ & $151(27.3)$ & $16(32.6)$ & Uncomplicated malaria $=0.73$ & 1 (reference) & \\
\hline GA & $280(50.6)$ & $22(44.9)$ & $276(49.9)$ & $24(49.0)$ & Severe malaria $=0.56$ & $0.69(0.34-1.43)$ & 0.27 \\
\hline AA & $124(22.4)$ & $10(20.4)$ & $126(22.8)$ & $9(18.4)$ & & $0.71(0.28-1.71)$ & 0.40 \\
\hline \multicolumn{8}{|c|}{ TLR9 T1486C rs187084 } \\
\hline$\pi$ & $316(57.2)$ & $26(53.1)$ & $315(57.0)$ & $26(53.0)$ & Uncomplicated malaria $=0.60$ & 1 (reference) & \\
\hline TC & $201(36.3)$ & 19 (38.8) & $203(36.7)$ & 19 (38.8) & Severe malaria $=0.84$ & $1.15(0.58-2.22)$ & 0.66 \\
\hline CC & $36(6.5)$ & $4(8.2)$ & $35(6.3)$ & $4(8.2)$ & & $1.35(0.32-4.21)$ & 0.59 \\
\hline \multicolumn{8}{|c|}{ TLR9 T1237C rs5743836 } \\
\hline$\pi$ & $226(40.9)$ & $19(38.8)$ & $219(39.6)$ & $20(40.8)$ & Uncomplicated malaria $=0.16$ & 1 (reference) & \\
\hline TC & $243(43.9)$ & $24(49.0)$ & $257(46.5)$ & $23(47.0)$ & Severe malaria $=0.71$ & $1.17(0.60-2.33)$ & 0.62 \\
\hline CC & $84(15.2)$ & $6(12.2)$ & $77(13.9)$ & $6(12.2)$ & & $0.85(0.27-2.31)$ & 0.74 \\
\hline \multicolumn{8}{|c|}{ TIRAP S180L rs8177374* } \\
\hline Ser/Ser & $520(94.0)$ & $47(95.9)$ & $520(94.0)$ & $47(95.9)$ & Uncomplicated malaria $=0.47$ & 1 (reference) & \\
\hline Ser/Leu & $33(6.0)$ & $2(4.1)$ & $32(5.8)$ & $2(4.1)$ & Severe malaria $=0.88$ & $0.67(0.07-2.77)$ & 0.59 \\
\hline Leu/Leu & $0(0.0)$ & $0(0.0)$ & $1(0.2)$ & $0(0.0)$ & & - & - \\
\hline \multicolumn{8}{|c|}{ FCGR2a H131R rs1801274 } \\
\hline $\mathrm{His} / \mathrm{His}$ & $97(17.5)$ & $11(22.5)$ & 99 (17.9) & $10(20.4)$ & Uncomplicated malaria $=0.62$ & 1 (reference) & \\
\hline $\mathrm{His} / \operatorname{Arg}$ & $276(49.9)$ & $23(46.9)$ & $272(49.2)$ & $24(49.0)$ & Severe malaria $=0.70$ & $0.73(0.33-1.74)$ & 0.42 \\
\hline Arg/Arg & 180 (32.6) & 15 (30.6) & $182(32.9)$ & 15 (30.6) & & $0.73(0.30-1.85)$ & 0.46 \\
\hline
\end{tabular}

Percentages in brackets. $\mathrm{Cl}$, confidence interval; HWE, Hardy-Weinberg equilibrium.

controls as well as between uncomplicated and severe malaria cases.

\section{Discussion}

The overall data seem to indicate that none of the SNPs of TLR4, TIRAP and FCGR2A genes studied, assessed in Burundian children, play a role in modulating susceptibility to malaria and disease severity in this population. Regarding SNPs of TLR9, this study suggests that whereas no role may be ascribable to TLR9 G1174A and TLR9 1486 C, TLR9 T1237C seems to be associated with an increased risk of developing malaria, although this SNP is not associated with different disease severity. Despite data regarding association between polymorphisms and severity of the disease have to be evaluated with caution because the total number of severe cases, particular those with cerebral malaria, is too small to permit to draw definitive conclusions, these findings seem to indicate that variation in the characteristics of TLR9 can play a role in conditioning the development of malaria. Consequently, they can be useful in the identification of children at higher risk of developing the disease and those for whom the preventive measures are strongly needed. However, all of these data have to be confirmed with larger studies because in most of the cases data collected with this study are only partially in agreement with those that have been already published at this regard.

Data on TLR4 Asp299Gly are quite different from those reported by other authors who, on the other hand, obtained results largely conflicting with each other. Mockenhaupt et al. reported that this polymorphism was associated with an increased risk of severe paediatric malaria without affecting the risk of infection [19]. On the contrary, Basu et al. demonstrated that TLR4 Asp299Gly was 
more common in patients with low parasitaemia and concluded that TLR4 could have a genetic role in controlling the blood infection level in mild malaria and could indirectly suggest a protective effect of TLR4 Asp299Gly against severe disease [20]. Similarly to the data here reported, Zakeri et al. [21] and Sam-Agudu et al. [18], respectively, reported a similar incidence of this SNP in children with mild malaria and in controls or in patients with cerebral malaria and in those with uncomplicated malaria. However, because the frequency of TLR4 Asp299Gly was always low in this study and in those previously reported, it is difficult to draw firm conclusions on the role of this SNP in susceptibility modulation to malaria and disease severity. On the other hand, different reports have also been published for another TLR4 SNP, Thr399lle, which some authors have associated with severe malaria, whereas others have observed with similar frequency in malaria patients and in healthy individuals [19-21]. Consequently, further studies are needed to establish whether TLR4 might effectively be involved in $P$. falciparum recognition and host response in humans and whether TLR4 could contribute to the control of infection.

Studies on TLR9 SNPs have also reported conflicting data. Sam-Agudu et al., studying children with cerebral malaria, found that patients with the $\mathrm{C}$ allele at -1237 and $\mathrm{G}$ allele at 1174 had higher levels of IFN- $\gamma$ than those without these alleles [18]. Because animal studies have implied a causal role for IFN- $\gamma$ in the pathogenesis of cerebral malaria and IFN- $\gamma$ levels were found higher in children with cerebral malaria who died as compared with survivors [12], these authors concluded that these TLR9 SNPs could play a role in modulating malaria severity. On the contrary, Campino et al., despite reporting evidence of cis-variants acting on gene expression, did not find any convincing association between TLR9 SNPs and malaria severity [24]. The data of this study agree only in part with those reported. As found by Ciampino et al. [24] but contrary to what was reported by Sam-Agudu et al. [18], no association between TLR9 SNPs and malaria severity was found, although a significant association between TLR9 $1237 \mathrm{C}$ and disease susceptibility was evidenced. In the past it was suggested that a possible explanation for the different data collected by Ciampino et al. [24] and Sam-Agudu et al. [18] could be found in the presence of different haemozoin loads in patients studied. TLR9 is located in the endoso$\mathrm{mal} /$ lysosomal compartment of the cells and recognizes nucleic acids of microbes including that of $P$. falciparum. Haemozoin is a dark-brown haem crystal produced by $P$. falciparum that functions as a carrier for $P$. falciparum DNA and functionally affects TLR9 response to parasite infection activating TLR9 proportionally to its concentration [9]. Several studies have documented that the haemozoin load is higher in children with SM compared with UM [3,37-39]. Unfortunately, these data seem to differ from this hypothesis because TLR9 T1237C was more common in children with malaria than in uninfected controls but had the same frequency in ill children, independent of disease severity. However, because the number of children with TLR9 SNPs was relatively low in all the studies, in this case too further studies are needed.

In this study, contrary to what was reported by some authors $[21,25]$, no protective effect of TIRAP Ser180Leu heterozygosity on susceptibility to and severity of malaria was found. Prevalence of heterozygosity in this study was quite similar to that reported by most of the authors that have studied African individuals. The differences between this study and those by Zakeri et al. [21] and Khor et al. [25] can be ascribed to differences in number of subjects enrolled. On the other hand, the lack of any relationship between the presence of TIRAP Ser180Leu heterozygosity and protection from malaria was also found by Leoratti et al. [23] and by Hamann et al. [26]. These latter authors reported a much reduced prevalence of both heterozygosity and homozygosity for this genetic variant in individuals from malaria holo-endemic Ghana and concluded that this finding strongly argued against an expected positive selection of a malaria-protective trait in Africa. However, in all the studies the number of subjects with homozygosity for TIRAP Ser180Leu was too small to be able to draw firm conclusions.

Regarding FCGR2A His131Arg, the data of this study are completely different from those reported by Schuldt et al. [27] who found that homozygosity for this SNP was positively associated with severe malarial anaemia but not with cerebral malaria or other major malaria complications. Several other studies have reported contrasting results on the role of this genetic variant on malaria infection and disease [22,28-31]. Different genetic backgrounds could explain these discrepancies. Alleles of FCGR2A and FCGR3B, which are involved in similar biological functions, can be in linkage disequilibrium and, consequently, may interfere with each other's evolution selection. Moreover, epistatic effects involving variants located in other genes in the FCGR gene cluster on chromosome 1q23-24 are likely to exist. Alternatively, once again it is possible that most of the studies were based on relatively small study groups providing limited statistical power to reveal significant associations with malaria and its complications.

\section{Conclusions}

Knowledge of the relationships between genetics, susceptibility to and severity of infections is essential to identify subjects at higher risk and to develop specific preventive measures. This is particularly import for malaria that remains one of the most important health problem in several geographic areas. This study shows that genetic polymorphisms of some factors involved in 
the innate immune response to $P$. falciparum infection have no influence in conditioning susceptibility to and severity of malaria in Burundian children. An exception might be represented by TLR9 T127C for which a significant correlation with an increased risk of developing malaria without any role in determining severity was found. This finding, when confirmed with further studies carried out with greater study samples, can permit to identify those subjects for whom preventive measure are strongly needed. Moreover, knowledge that same aspects of the innate immunity can have different efficacy in facing infectious agents can be of value in the preparation of specific vaccines when immune response evoked by the antigens included in the vaccines involves the factors with modified activity. This has to be considered also in the preparation of the developing malaria vaccines.

\section{Abbreviations \\ CRP: C reactive protein; HWE: Hardy-Weinberg equilibrium; SNPs: single nucleotide polymorphisms; TIRAP: Toll-interleukin 1 receptor domain containing adaptor protein; TLRs: toll-like receptors.}

\section{Competing interests}

The authors declare that they have no competing interest. The study was partly supported by Bando Giovani Ricercatori 2007 (Italian Ministry of Health) and partly by ABM Onlus (that is a non profit organization).

\section{Acknowledgements}

We would like to thank the medical and nursing staff of Kiremba Hospital particularly Dr Marcellin and Dr Pharaon. Our thanks also go to Giovanni Gobbi and the ASCOM Society for giving us the opportunity to work in Kiremba. Last but not least, we would like thank all the families who agreed to participate in this study.

\section{Author details}

'Pediatric Clinic 1, Università degli Studi di Milano, Fondazione IRCCS Ca' Granda Ospedale Maggiore Policlinico, Via Commenda 9, 20122, Milan, Italy. ${ }^{2}$ Genetic Unit, Università degli Studi di Milano, Milan, Italy. ${ }^{3}$ Department of Epidemiology, Istituto di Ricerche Farmacologiche Mario Negri, Milan, Italy.

\section{Authors' contributions}

SE and NP designed the study and co-wrote the manuscript. CGM, AZ, CD, $\mathrm{AS}$ and $\mathrm{LT}$ carried out the laboratory assays. EB, AL, MS and MG visited patients and controls, collected the samples and entered the data in the database. MM interpreted results of genetic analyses. CP statistically analysed the data. All the authors read and approved the final manuscript.

Received: 20 April 2012 Accepted: 12 June 2012

Published: 12 June 2012

\section{References}

1. Snow RW, Guerra CA, Noor AM, Myint HY, Hay Sl: The global distribution of clinical episodes of Plasmodium falciparum malaria. Nature 2005, 434:214-217.

2. White NJ, Ho M: The pathophysiology of malaria. Adv Parasitol 1992, 31:83-173.

3. Fortin A, Stevenson MM, Gros P: Susceptibility to malaria as a complex trait: big pressure from a tiny creature. Hum Mol Genet 2002, 11:2469-2478.

4. Ishii KJ, Uematsu S, Akira S: 'Toll' gates for future immunotherapy. Curr Pharm Des 2006, 12:4135-4142.

5. Re F, Strominger JL: Toll-like receptor 2 (TLR2) and TLR4 differentially activate human dendritic cells. J Biol Chem 2001, 276:37692-37699.

6. Jaramillo M, Godbout M, Olivier M: Hemozoin induces macrophage chemokine expression through oxidative stress-dependent andindependent mechanisms. J Immunol 2005, 174:475-484.

7. Krishnegowda G, Hajjar AM, Zhu J, Douglass EJ, Uematsu S, Akira S, Woods AS, Gowda DC: Induction of proinflammatory responses in macrophages by the glycosylphosphatidylinositols of Plasmodium falciparum: cell signaling receptors, glycosylphosphatidylinositol (GPI) structural requirement, and regulation of GPI activity. J Biol Chem 2005, 280:8606-8616.

8. Nebl T, De Veer MJ, Schofield L: Stimulation of innate immune responses by malarial glycosylphospatidylinositol via pattern recognition receptors. Parasitology 2005, 130:S45-S62.

9. Parroche P, Lauw FN, Goutagny N, Latz E, Monks BG, Visintin A, Halmen KA, Lamphier M, Olivier M, Bartholomeu DC, Gazzinelli RT, Golenbock DT: Malaria hemozoin is immunologically inert but radically enhances innate responses by presenting malaria DNA to Toll-like receptor 9. Proc Natl Acad Sci USA 2007, 104:1919-1924.

10. Grau GE, Taylor TE, Molyneux ME, Wirima JJ, Vassalli P, Hommel M, Lambert $\mathrm{PH}$ : Tumor necrosis factor and disease severity in children with falciparum malaria. N Engl J Med 1989, 320:1586-1591.

11. Kwiatkowski D, Hill AV, Sambou I, Twumasi P, Castracane J, Manogue KR, Cerami A, Brewster DR, Greenwood BM: TNF concentration in fatal cerebral, non-fatal cerebral, and uncomplicated Plasmodium falciparum malaria. Lancet 1990, 336:1201-1204.

12. John CC, Opika-Opoka R, Byarugaba J, Idro R, Boivin MJ: Low levels of RANTES are associated with mortality in children with cerebral malaria. J Infect Dis 2006, 194:837-845.

13. Akanmori BD, Kurtzhals JA, Goka BQ, Adabayeri V, Ofori MF, Nkrumah FK, Behr C, Hviid L: Distinct patterns of cytokine regulation in discrete clinical forms of Plasmodium falciparum malaria. Eur Cytokine Netw 2000, 11:113-118.

14. Tchinda VH, Tadem AD, Tako EA, Tene G, Fogako J, Nyonglema P, Sama G, Zhou A, Leke RG: Severe malaria in Cameroonian children: correlation between plasma levels of three soluble inducible adhesion molecules and TNF-alpha. Acta Trop 2007, 102:20-28.

15. Greene JA, Moormann AM, Vulule J, Bockrie MJ, Zimmerman PA, Kazura JW: Toll-like receptor polymorphisms in malaria-endemic populations. Malar J 2009, 8:50.

16. Yamamoto M, Sato S, Hemmi H, Sanjo H, Uematsu S, Kaisho T, Hoshino K, Takeuchi O, Kobayashi M, Fujita T, Takeda K, Akira S: Essential role for TIRAP in activation of the signaling cascade shared by TLR2 and TLR4. Nature 2002, 420:324-329.

17. Bodman-Smith KB, Gregory RE, Harrison PT, Raynes JG: FcgammaRlla expression with FcgammaRl results in C-reactive protein - and lgGmediated phagocytosis. J Leukol Biol 2004, 75:1029-1035.

18. Sam-Agudu NA, Greene JA, Opoka RO, Kazura JW, Boivin MJ, Zimmerman PA, Riedesel MA, Bergemann TL, Schimmenti LA, John CC: TLR9 polymorphisms are associated with altered IFN-gamma levels in children with cerebral malaria. Am J Trop Med Hyg 2010, 82:548-555.

19. Mockenhaupt FP, Hamann L, von Gaertner C, Bedu-Addo G, von Kleinsorgen C, Schumann RR, Bienzle U: Common polymorphisms of tolllike receptors 4 and 9 are associated with the clinical manifestation of malaria during pregnancy. J Infect Dis 2006, 194:184-188.

20. Basu M, Maji AK, Chakraborty A, Banerjee R, Mullick S, Saha P, Das S, Kanjila SD, Sengupta S: Genetic association of Toll-like-receptor 4 and tumor necrosis factor-alpha polymorphisms with Plasmodium falciparum blood infection levels. Infect Genet Evol 2010, 10:686-696.

21. Zakeri S, Pirahmadi S, Mehrizi AA, Djadid ND: Genetic variation of TLR-4, TLR-9 and TIRAP genes in Iranian malaria patients. Malar I 2011, 10:77.

22. Sinha S, Mishra SK, Sharma S, Patibandla PK, Mallick PK, Sharma SK, Mohanty S, Pati SS, Mishra SK, Ramteke BK, Bhatt R, Joshi H, Dash AP, Ahuja RC: Awasthi S; Indian Genome Variation Consortium, Venkatesh V. Habib S: Polymorphisms of TNF-enhancer and gene for FcgammaRlla correlate with the severity of falciparum malaria in the ethnically diverse Indian population. Malar J 2008, 7:13

23. Leoratti FM, Farias L, Alves FP, Suarez-Mútis MC, Coura JR, Kalil J, Camargo EP, Moraes SL, Ramasawmy R: Variants in the toll-like receptor signaling pathway and clinical outcomes of malaria. J Infect Dis 2008, 198:772-780.

24. Campino S, Forton J, Auburn S, Fry A, Diakite M, Richardson A, Hull J, Jallow M, Sisay-Joof F, Pinder M, Molyneux ME, Taylor TE, Rockett K, Clark TG, Kwiatkowski DP: TLR9 polymorphisms in African populations: no association with severe malaria, but evidence of cis -variants acting on gene expression. Malar J 2009, 8:44.

25. Khor CC, Chapman SJ, Vannberg FO, Dunne A, Murphy C, Ling EY, Frodsham AJ, Walley AJ, Kyrieleis O, Khan A, Aucan C, Segal S, Moore CE, Knox K, Campbell SJ, Lienhardt C, Scott A, Aaby P, Sow OY, Grignani RT, Sillah J, Sirugo G, Peshu N, Williams TN, Maitland K, Davies RJ, Kwiatkowski DP, Day NP, Yala D, Crook DW, Marsh K, Berkley JA, O'Neill LA, Hill AV: A Mal 
functional variant is associated with protection against invasive pneumococcal disease, bacteremia, malaria and tuberculosis. Nat Genet 2007, 39:523-528.

26. Hamann L, Kumpf O, Schuring RP, Alpsoy E, Bedu-Addo G, Bienzle U, Oskam L, Mockenhaupt FP, Schumann RR: Low frequency of the TIRAP S180L polymorphism in Africa, and its potential role in malaria, sepsis, and leprosy. BMC Med Genet 2009, 10:65.

27. Schuldt K, Esser C, Evans J, May J, Timmann C, Ehmen C, Loag W, Ansong D, Ziegler A, Agbenyega T, Meyer CG, Horstmann RD: FCGR2A functional genetic variant associated with susceptibility to severe malarial anaemia in Ghanaian children. J Med Genet 2010, 47:471-475.

28. Nasr A, Iriemenam NC, Troye-Blomberg M, Giha HA, Balogun HA, Osman OF, Montgomery SM, EIGhazali G, Berzins K: Fc gamma receptor Ila (CD32) polymorphism and antibody responses to asexual blood-stage antigens of Plasmodium falciparum malaria in Sudanese patients. Scand I Immunol 2007, 66:87-96.

29. Cooke GS, Aucan C, Walley AJ, Segal S, Greenwood BM, Kwiatkowski DP, Hill $\mathrm{AV}$ : Association of Fcgamma receptor lla (CD32) polymorphism with severe malaria in West Africa. Am J Trop Med Hyg 2003, 69:565-568.

30. Shi YP, Nahlen BL, Kariuki S, Urdahl KB, McElroy PD, Roberts JM, Lal AA: Fcgamma receptor lla (CD32) polymorphism is associated with protection of infants against high-density Plasmodium falciparum infection. VII. Asembo Bay Cohort Project. J Infect Dis 2001, 184:107-111.

31. Ouma C, Keller CC, Opondo DA, Were T, Otieno RO, Otieno MF, Orago AS: Ong'Echa JM, Vulule JM, Ferrell RE, Perkins DJ: Association of FCgamma receptor IIA (CD32) polymorphism with malarial anemia and highdensity parasitemia in infants and young children. Am J Trop Med Hyg 2006, 74:573-577.

32. World Health Organization: Severe falciparum malaria. Trans $R$ Soc Trop Med Hyg 2000, 94(Suppl 1):S1-S90.

33. Livak KJ, Marmaro J, Todd JA: Towards fully automated genome-wide polymorphism screening. Nat Genet 1995, 9:341-342.

34. Shen GQ, Abdullah KG: Wang Qk: The TaqMan method for SNP genotyping. Methods Mol Biol 2009, 578:293-306.

35. Engels WR: Exact tests for Hardy-Weinberg proportions. Genetics 2009, 183:1431-1441.

36. Michael C: A simple calculator to determine whether observed genotype frequencies are consistent with Hardy-Weinberg equilibrium.: ; 2008. http:// www.tufts.edu/ mcourt01/Documents/Court lab - HW calculator.xls.

37. Amodu OK, Adeyemo AA, Olumese PE, Gbadegesin RA: Intraleucocytic malaria pigment and clinical severity of malaria in children. Trans $R$ Soc Trop Med Hyg 1998, 92:54-56

38. Lyke KE, Diallo DA, Dicko A, Kone A, Coulibaly D, Guindo A, Cissoko Y, Sangare L, Coulibaly S, Dakouo B, Taylor TE, Doumbo OK, Plowe CV: Association of intraleukocytic Plasmodium falciparum malaria pigment with disease severity, clinical manifestations, and prognosis in severe malaria. Am J Trop Med Hyg 2003, 69:253-259.

39. Nguyen PH, Day N, Pram TD, Ferguson DJ, White NJ: Intraleucocytic malaria pigment and prognosis in severe malaria. Trans $R$ Soc Trop Med Hyg 1995, 89:200-204.

doi:10.1186/1475-2875-11-196

Cite this article as: Esposito et al:: Role of polymorphisms of toll-like receptor (TLR) 4, TLR9, toll-interleukin 1 receptor domain containing adaptor protein (TIRAP) and FCGR2A genes in malaria susceptibility and severity in Burundian children. Malaria Journal 2012 11:196.

\section{Submit your next manuscript to BioMed Central and take full advantage of:}

- Convenient online submission

- Thorough peer review

- No space constraints or color figure charges

- Immediate publication on acceptance

- Inclusion in PubMed, CAS, Scopus and Google Scholar

- Research which is freely available for redistribution 